\title{
Survival analysis and visual outcome in a large series of corneal transplants in India
}

\author{
Lalit Dandona, Thomas J Naduvilath, M Janarthanan, Krishnan Ragu, Gullapalli N Rao
}

Public Health Ophthalmology Service, L V Prasad

Eye Institute, Hyderabad, India L Dandona

T J Naduvilath

M Janarthanan

Cornea Service, L V Prasad Eye Institute, Hyderabad, India

K Ragu

G N Rao

Correspondence to: Lalit Dandona, MD, MPH, Public Health

Ophthalmology Service, L V

Prasad Eye Institute, Road

No 2, Banjara Hills,

Hyderabad - 500 034, India.

Accepted for publication 14 May 1997

\begin{abstract}
Aim/background-The public health significance of corneal transplantation in dealing with corneal blindness in the developing world would depend upon the survival rate of transplants. This study was done to analyse the survival rate of corneal transplants in a large series in India, and to evaluate the influence of various risk factors on transplant survival.

Methods-The records of a series of $\mathbf{1 7 2 5}$ cases of corneal transplants carried out during $1987-95$ at a tertiary eye care institution in India were reviewed. The Kaplan-Meier method was used to determine 5 year survival rates of corneal transplants performed for the various categories of preoperative diagnosis. Multivariate Cox proportional hazards regression was used to assess how preoperative diagnosis, socioeconomic status, age, sex, vascularisation of host cornea, quality of donor cornea, and training status of surgeon influenced transplant survival. The effect of these variables on visual outcome was assessed using multiple logistic regression.
\end{abstract}

Results-The survival rates at 1,2 , and 5 years for all corneal transplants performed for the first time in 1389 cases were $79.6 \%(95 \%$ confidence interval = $77.3-81.9 \%), \quad 68.7 \% \quad(65.7-71.7 \%)$ and $46.5 \%(41.7-51.3 \%)$. The 5 year survival rate was highest if the corneal transplant was done for keratoconus (95.1\% (84.8$100 \%)$ ) and lowest if carried out for previous transplant failure $(21.2 \%)(13.8-$

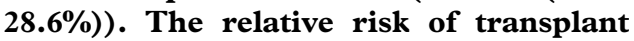
failure was higher if the preoperative diagnosis was previous transplant failure (2.04 (1.62-2.55)), aphakic bullous keratopathy (1.78 (1.38-2.28)), corneal clouding due to miscellaneous causes including congenital conditions and glaucoma (1.63 (1.21-2.19)), or adherent leucoma (1.11 (0.81-1.51)) than for the other preoperative diagnoses. Patients with lower socioeconomic status had higher relative risk of transplant failure (1.28 (1.16$1.42)$ ), as did patients $<10$ years of age (1.42 (1.23-1.64)). Higher relative risk of transplant failure was associated with vascularisation of the host cornea before transplantation (1.15 (1.04-1.27)), and with the use of fair quality donor cornea for transplantation compared with excellent, very good, or good quality donor cornea (1.26 (1.06-1.52)). Before corneal transplant $80.2 \%$ of the eyes were blind (visual acuity $<3 / 60$ ), whereas at last follow up $41.8 \%$ eyes were blind. The odds of having visual acuity $>6 / 18$ were higher if the transplant was done for keratoconus (9.99 (6.10-16.36)) or corneal dystrophies (1.77 (1.21-2.58)) than for the other preoperative diagnoses.

Conclusion-Reasonable success with corneal transplantation is possible in the developing world if data from this part of the world regarding the different survival rates for the various preoperative diagnoses and the influence of risk factors on transplant survival and visual outcome are taken into account while determining priority for transplant cases in the present situation of limited availability of donor corneas.

(Br F Ophthalmol 1997;81:726-731)

Blindness and visual impairment due to corneal diseases is a significant public health problem in the developing world. ${ }^{1}$ Visual rehabilitation with corneal transplantation (penetrating keratoplasty) may be a possibility in many of these cases. In order to assess the role that corneal transplantation could play in visual rehabilitation of the corneal blind in the developing world, data on the survival rate of corneal transplants in the developing world are required. Apart from one recent report on 216 cases of corneal transplants in Africa, ${ }^{2}$ to our knowledge, reliable peer reviewed data regarding survival of transplants in a large series from the developing world are currently not available.

We analysed the survival of corneal transplants in a series of 1725 cases done during 1987-95 at a tertiary eye care institution in India. The influence of potential risk factors on transplant failure and visual outcome was also analysed in this series. These data were expected to provide some basis for assessing the potential public health significance of corneal transplantation in dealing with corneal blindness in the developing world.

Materials and methods

Data were obtained by reviewing the patient records for a series of 1725 corneal transplants (penetrating keratoplasties) carried out at the L V Prasad Eye Institution, Hyderabad, India, from its beginning in mid 1987 to October 1995. Details of the indications for all 1964 corneal transplants performed during this period at this institution have been reported 
elsewhere. ${ }^{3}$ Two hundred and thirty nine corneal transplants done during this period for active infectious keratitis were not included in the present report because the nature and purpose of transplants for this indication are quite different from the rest. The transplants done in cases of active infectious keratitis are usually larger and their immediate purpose is to provide structural integrity. This is in contrast with the other indications for corneal transplantation where the purpose is to rehabilitate vision.

The survival rates of corneal transplants performed for the various indications or preoperative diagnoses were determined using the Kaplan-Meier method. ${ }^{4}$ The effect on transplant survival of preoperative diagnosis, socioeconomic status, age, sex, vascularisation of host cornea, quality of donor cornea, and whether the transplantation was done by a surgeon during or after fellowship training, was first studied with univariate analysis for categorical data, ${ }^{5}{ }^{6}$ followed by multivariate analysis using Cox proportional hazards regression ${ }^{7}$ in order to assess the effect of these variables after adjusting for one another. The multivariate model used to evaluate the effect of these variable on visual outcome was multiple logistic regression. ${ }^{8}$

Assessment of the economic status of each patient is carried out at our institution to determine whether the patient can pay for the services. If a patient cannot pay because of his/ her socioeconomic status, all services at our institution are provided free. For the present report, the patients who could not pay for the services were considered to have lower socioeconomic status, and those who could pay were considered to have higher socioeconomic status. Patients were initially divided into age groups of $<10,11-20,21-49$, and $\geqslant 50$ years to study the effect of age on transplant survival.

Vascularisation of the host cornea before transplantation was divided into superficial, if present on the corneal surface, and deep, if present in the corneal stroma. Only the blood vessels growing more than $2 \mathrm{~mm}$ from the limbus towards the centre of the cornea were considered. Superficial vascularisation was considered for analysis if three or more vessels were present. Presence of even a single deep vessel was considered for analysis, and the extent of deep vascularisation was initially divided into groups of $<3,3-6,>6-9,>9$ clock hours of the cornea. If both deep and superficial vascularisation were present in the same cornea, only the former was considered for analysis.

Quality of the donor cornea used for transplantation was graded as excellent, very good, good, or fair based on standardised slit-lamp evaluation of all layers of the cornea before the surgery.

The corneal transplant was considered to have failed if it did not retain optical clarity for any reason, and attempts to improve this did not respond to any therapy.

Blindness in an eye was defined using the visual acuity criterion of $<3 / 60$ recommended by the World Health Organisation. ${ }^{9}$
Table 1 Indications for corneal transplantation

\begin{tabular}{lcc}
\hline Preoperative diagnosis & Number & Percentage \\
\hline Corneal scar other than adherent & & \\
$\quad$ leucoma & 404 & 23.4 \\
Previous transplant failure & 336 & 19.5 \\
Aphakic bullous keratopathy & 231 & 13.4 \\
Pseudophakic bullous keratopathy & 209 & 12.1 \\
Corneal dystrophies & 165 & 9.6 \\
Adherent leucoma & 147 & 8.5 \\
Keratoconus & 118 & 6.8 \\
Corneal clouding from miscellaneous & & \\
$\quad$ causes including congenital & 115 & 6.7 \\
$\quad$ conditions and glaucoma & 1725 & 100 \\
\hline Total & & \\
\hline
\end{tabular}

^Adherent leucoma is corneal scar with iris incarceration.

Table 2 Percentage of cases lost to follow up after corneal transplantation

\begin{tabular}{ll}
\hline Preoperative diagnosis & $\begin{array}{l}\text { Percentage } \\
\text { of cases }\end{array}$ \\
\hline Corneal scar other than adherent leucoma & 26.7 \\
Previous transplant failure & 14.3 \\
Aphakic bullous keratopathy & 25.1 \\
Pseudophakic bullous keratopathy & 24.4 \\
Corneal dystrophies & 13.3 \\
Adherent leucoma & 27.9 \\
Keratoconus & 20.3 \\
Corneal clouding from miscellaneous causes & \\
including congenital conditions and glaucoma & 24.3 \\
\hline
\end{tabular}

One of the assumptions of the statistical tests used is that the observations within a category should be independent of one another. Since the outcomes in two eyes of the same patient are likely to be correlated, ${ }^{10}$ only one eye was chosen randomly for statistical analysis if a patient had corneal transplantation in both eyes. Similarly, to meet the requirement of independence of observations within a category only the first repeat transplant was included in the statistical analysis if an eye had more than one repeat transplants. To determine statistical significance $95 \%$ confidence intervals were calculated for the estimates.

\section{Results}

The categories of preoperative diagnosis for the 1725 corneal transplants analysed in this series are shown in Table 1. A detailed description of these preoperative diagnoses has been reported elsewhere. ${ }^{3}$ These 1725 transplants were performed on 1397 patients, $958(68.6 \%)$ males and 439 (31.4\%) females. Eighty nine patients had transplants in both eyes; 1205 $(69.9 \%)$ transplants were performed on patients with higher socioeconomic status and $520(30.1 \%)$ on those with lower socioeconomic status; 41 years was the mean as well as the median age at which transplants were done in this series, and the age range was 7 days to 90 years. The follow up after corneal transplantation ranged from 3 to 96 months, with a mean of 22.4 months. Overall, $22 \%$ of cases were lost to follow up after transplantation. The percentage lost to follow up for the different preoperative diagnoses are shown in Table 2. The number of cases for which data were available at the various time intervals after transplantation are shown in Table 3.

For all the 1389 first time corneal transplants considered together the 1,2 , and 5 year survival rates were $79.6 \%$ (95\% confidence 
Table 3 Number of cases for which data were available at various time intervals after corneal transplantation

\begin{tabular}{|c|c|c|c|c|c|c|c|}
\hline \multirow[b]{2}{*}{ Preoperative diagnosis } & \multicolumn{7}{|c|}{ Number of cases at* } \\
\hline & Start & 6 months & 1 year & 2 years & 3 years & 4 years & 5 years \\
\hline \multicolumn{7}{|l|}{ Corneal scar other than } & 82 \\
\hline Previous transplant failure & 336 & 310 & 281 & 223 & 190 & 137 & 84 \\
\hline Aphakic bullous keratopathy & 231 & 212 & 181 & 122 & 88 & 63 & 44 \\
\hline \multicolumn{8}{|l|}{ Pseudophakic bullous } \\
\hline keratopathy & 209 & 185 & 144 & 84 & 54 & 31 & 23 \\
\hline Corneal dystrophies & 165 & 155 & 143 & 107 & 77 & 56 & 35 \\
\hline Adherent leucoma & 147 & 132 & 105 & 75 & 56 & 48 & 25 \\
\hline Keratoconus & 118 & 106 & 84 & 58 & 35 & 27 & 17 \\
\hline \multicolumn{8}{|l|}{$\begin{array}{l}\text { Corneal clouding from } \\
\text { miscellaneous causes } \\
\text { including congenital }\end{array}$} \\
\hline conditions and glaucoma & 115 & 104 & 90 & 61 & 47 & 37 & 27 \\
\hline Total & 1725 & 1565 & 1334 & 938 & 700 & 523 & 337 \\
\hline
\end{tabular}

*This number includes cases that had transplant failure until each indicated time.

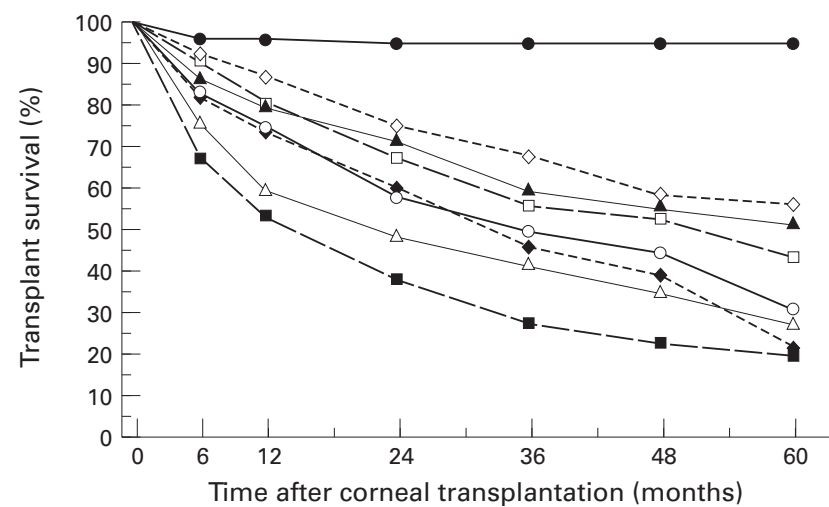

Figure 1 Corneal transplant survival rates for the different preoperative diagnoses determined with the Kaplan-Meier method. Preoperative diagnoses: 1, keratoconus; 2 , corneal dystrophies; 3, corneal scar other than adherent leucoma; 4, pseudophakic bullous keratopathy; 5, adherent leucoma; 6, aphakic bullous keratopathy; 7, corneal clouding from miscellaneous causes including congenital conditions and glaucoma; 8, previous transplant failure.
Table 4 Effect of preoperative diagnosis, socioeconomic status, age, vascularisation of host cornea, and quality of donor cornea on transplant failure with Cox proportional hazards regression analysis

\begin{tabular}{|c|c|c|}
\hline & $\begin{array}{l}\text { Relative } \\
\text { risk }\end{array}$ & $\begin{array}{l}95 \% \text { Confidence } \\
\text { interval }\end{array}$ \\
\hline \multicolumn{3}{|l|}{ Preoperative diagnosis } \\
\hline Keratoconus & 0.15 & $0.06-0.37$ \\
\hline Corneal dystrophies & 0.74 & $0.53-1.03$ \\
\hline \multicolumn{3}{|l|}{ Corneal scar other than } \\
\hline adherent leucoma & 0.91 & $0.72-1.16$ \\
\hline \multicolumn{3}{|l|}{ Pseudophakic bullous } \\
\hline keratopathy & 1.00 & \\
\hline Adherent leucoma & 1.11 & $0.81-1.51$ \\
\hline \multicolumn{3}{|l|}{$\begin{array}{l}\text { Corneal clouding due to } \\
\text { miscellaneous causes } \\
\text { including congenital }\end{array}$} \\
\hline conditions and glaucoma & 1.63 & $1.21-2.19$ \\
\hline Aphakic bullous keratopathy & 1.78 & $1.38-2.28$ \\
\hline Previous transplant failure & 2.04 & $1.62-2.55$ \\
\hline \multicolumn{3}{|l|}{ Socioeconomic status } \\
\hline Higher & 1.00 & \\
\hline Lower & 1.28 & $1.16-1.42$ \\
\hline \multicolumn{3}{|l|}{ Age } \\
\hline$>10$ years & 1.00 & \\
\hline$\leqslant 10$ years & 1.42 & $1.23-1.64$ \\
\hline \multicolumn{3}{|l|}{ Vascularisation of host cornea } \\
\hline No & 1.00 & \\
\hline Yes & 1.15 & $1.04-1.27$ \\
\hline \multicolumn{3}{|l|}{ Quality of donor cornea } \\
\hline Excellent, very good, good & 1.00 & \\
\hline Fair & 1.26 & $1.06-1.52$ \\
\hline
\end{tabular}

in Table 4. Pseudophakic bullous keratopathy was used as the reference preoperative diagnosis in the Cox model since the survival curve for this was closest to the survival curve for all first time transplants considered together. The univariate and initial multivariate analyses suggested that the survival rates for the 11-20, $21-49$, and $\geqslant 50$ years age groups, comprising $11.4 \%, 38.6 \%$, and $39.2 \%$ transplants, respectively, were not significantly different from one another. Therefore, these age groups were combined for comparison with the $<10$ years group (10.8\% transplants) in the final Cox regression model. For the same reason the excellent, very good, and good donor cornea grades, comprising $13.5 \%, 26.5 \%$, and $55.3 \%$ transplants, respectively, were combined for comparison with the fair donor cornea grade ( $4.7 \%$ transplants).

Vascularisation of the host cornea before transplantation was present in $41.3 \%$ of the cases, including $29 \%$ with superficial and $12.3 \%$ with deep vascularisation. Univariate analysis showed that deep vascularisation by itself was associated with significantly higher odds of graft failure up to 3 years $(p=0.042)$, but deep vascularisation by itself did not have a significant effect on graft survival in the multivariate analysis and so the four categories of the extent of deep vascularisation were not analysed separately in the multivariate models.

Sex of the patient, and whether the corneal transplant was performed by a surgeon after having completed fellowship training $(89.6 \%$ cases) or during fellowship training, did not significantly affect transplant survival in the multivariate analysis.

The distribution of visual acuity before corneal transplantation and at last follow up is shown in Table 5 . Before transplantation, $80.2 \%$ of the eyes were blind (visual acuity $<3 / 60$ ). The percentage of blind eyes dropped to 41.8 at last follow up. The causes of blindness at last follow relative risks of transplant failure for these variables after adjusting for one another are shown 
Table 5 Distribution of visual acuity before corneal transplantation and at last follow up for all cases considered together

\begin{tabular}{lrrrrr}
\hline & \multicolumn{2}{c}{ Preoperative } & & \multicolumn{2}{c}{ Last follow up } \\
\cline { 2 - 3 } \cline { 6 - 6 } Visual acuity & No & $(\%)$ & & No & $(\%)$ \\
\hline$\geqslant 6 / 18$ & 27 & $(1.7)$ & & 447 & $(28.0)$ \\
$<6 / 18-6 / 36$ & 99 & $(6.2)$ & & 246 & $(15.4)$ \\
$<6 / 36-6 / 60$ & 108 & $(6.8)$ & & 129 & $(8.1)$ \\
$<6 / 60-3 / 60$ & 82 & $(5.1)$ & & 107 & $(6.7)$ \\
$<3 / 60$ & 1277 & $(80.2)$ & & 668 & $(41.8)$ \\
Total & $1593^{\star}$ & $(100.0)$ & & $1597^{\star}$ & $(100.0)$ \\
\end{tabular}

*Totals do not add up to 1725 because preoperative visual acuity could not be assessed in 106 children and was not available for 26 patients, and visual acuity at last follow up could not be assessed in 89 children and was not available for 39 patients.

up in 668 eyes included those related to cornea in $538(80.5 \%)$, retina $39(5.8 \%)$, amblyopia 26 $(3.9 \%)$, glaucoma $17(2.5 \%)$, posterior capsule opacity seven $(1.0 \%)$, cataract three $(0.4 \%)$, other causes $10(1.5 \%)$, and indeterminate cause $28(4.2 \%)$. Table 6 shows the risk factors that had a significant effect on the eye being blind after transplantation as determined by multiple logistic regression analysis. The risk factors having a significant effect on visual acuity of $\geqslant 6 / 18$ at last follow up after transplantation are shown in Table 7 . This visual acuity of $\geqslant 6 / 18$ was present in $81.2 \%$ of the eyes which had transplants carried out for keratoconus and $43 \%$ for corneal dystrophies compared with $21.6 \%$ for all other preoperative diagnoses combined.

\section{Discussion}

This study documents, for the first time to our knowledge, the survival rates in a large series of corneal transplants and the influence of risk

Table 6 Effect of preoperative diagnosis, socioeconomic status, and age on eye being blind (visual acuity <3/60) at last follow up after transplantation with multiple logistic regression analysis

\begin{tabular}{lll}
\hline & Odds ratio & 95\% Confidence interval \\
\hline Preoperative diagnosis & 0.12 & $0.06-0.28$ \\
$\quad$ Keratoconus & 0.51 & $0.33-0.78$ \\
$\quad$ Corneal dystrophies & 0.92 & $0.70-1.21$ \\
$\quad$ Corneal scar other than adherent leucoma & 1.00 & \\
$\quad \begin{array}{l}\text { Pseudophakic bullous keratopathy } \\
\quad \text { Adherent leucoma }\end{array}$ & 1.58 & $1.08-2.32$ \\
$\quad$ Corneal clouding from miscellaneous causes & & \\
$\quad$ including congenital conditions and glaucoma & 1.68 & $1.10-2.57$ \\
$\quad$ Aphakic bullous keratopathy & 1.99 & $1.48-2.67$ \\
$\quad$ Previous transplant failure & 2.89 & $2.11-3.96$ \\
Socioeconomic status & 1.00 & \\
$\quad$ Higher & 2.17 & $1.62-2.90$ \\
$\quad$ Lower & 1.00 & \\
Age & 1.86 & $1.09-3.18$ \\
$\quad$ 10 years & & \\
$\quad \leqslant 10$ years & & \\
\hline
\end{tabular}

Table 7 Effect of preoperative diagnosis and socioeconomic status on visual acuity $\geqslant 6 / 18$ at last follow up after transplantation with multiple logistic regression analysis

\begin{tabular}{lll}
\hline & Odds ratio & 95\% Confidence interval \\
\hline Preoperative diagnosis & & \\
$\quad$ Keratoconus & 9.99 & $6.10-16.36$ \\
$\quad$ Corneal dystrophies & 1.77 & $1.21-2.58$ \\
$\quad$ Corneal scar other than adherent leucoma & 1.17 & $0.89-1.54$ \\
$\quad \begin{array}{l}\text { Pseudophakic bullous keratopathy } \\
\text { Adherent leucoma }\end{array}$ & 0.94 & $0.61-1.44$ \\
$\quad$ Corneal clouding from miscellaneous causes & & \\
$\quad$ including congenital conditions and glaucoma & 0.47 & $0.27-0.82$ \\
$\quad$ Aphakic bullous keratopathy & 0.37 & $0.26-0.54$ \\
$\quad$ Previous transplant failure & 0.37 & $0.24-0.55$ \\
Socioeconomic status & 1.00 & \\
$\quad$ Higher & 0.45 & $0.32-0.65$ \\
$\quad$ Lower &
\end{tabular}

factors on transplant survival and visual outcome in the developing world. The presence of a large number of people blind due to corneal diseases in the developing world is a significant public health problem. ${ }^{1}$ Prevention of causes that lead to corneal blindness would be the preferred approach for this problem in the long term. However, until these prevention strategies become effective and make a significant difference, corneal transplantation is the only option for visual rehabilitation of those currently blind from corneal diseases. The important question related to this issue currently is whether corneal transplantation can be a successful procedure from a public health perspective for the many who have corneal blindness in the developing world. In order to address this question, data are needed from the developing world that analyse the survival rate of corneal transplants and assess the influence of risk factors on transplant survival and visual outcome. The purpose of the present study was to provide these data from a large series of corneal transplants performed at an institution in the developing world.

The 1, 2, and 5 year survival rates for all the first time corneal transplants considered together in our series were $79.6 \%, 68.7 \%$, and $46.5 \%$, respectively. The survival rates were higher for some categories of preoperative diagnosis compared with the others. The excellent $95.1 \%$ survival rate for keratoconus at 5 years in this series is similar to that reported from the developed world. ${ }^{11-13} \mathrm{~A}$ transplant survival rate of $87.4 \%$ at 2 years has been reported for 108 cases of keratoconus in Africa. ${ }^{2}$ For the preoperative diagnosis categories of previous graft failure, aphakic bullous keratopathy, corneal clouding from miscellaneous causes including congenital conditions and glaucoma, and adherent leucoma, the risk of transplant failure was higher than for the other categories of preoperative diagnosis. The success of corneal transplantation has been documented to be relatively poor in the developed world too for preoperative diagnosis of previous transplant failure $\mathrm{e}^{12-17}$ and congenital conditions. $^{1819}$

In our series, the survival of transplants performed for aphakic bullous keratopathy was quite poor, $21.5 \%$ survived at 5 years. This is related to the poor eye care infrastructure and quality of surgical training in many parts of India and the developing world. A large proportion of cataract surgery in India is still being carried out with the intracapsular technique without intraocular lens implantation. ${ }^{20}$ This reflects the general trend in the developing world. A significant proportion of this surgery is being performed under suboptimal conditions such as makeshift arrangements for mass surgery, referred to as eye camps. This, combined with the fact that a large proportion of ophthalmic surgeons in India are not adequately trained in the extracapsular cataract extraction technique with posterior chamber intraocular lens implantation, leads to poor quality of surgery in a large number of cases with subsequent complications including corneal decompensa- 
tion. Realisation that resources spent on improving the infrastructure and training for cataract surgery in the developing world would be a good cost effective investment for society, ${ }^{21}$ has led to the approval of a US $\$ 140$ million loan by the World Bank to seven states in India for this purpose.

Transplants performed in our series for adherent leucomas had a relatively poor survival of $31.5 \%$ at 5 years. Incarceration of iris in the corneal scar implies a history of corneal perforation being sealed by the iris with subsequent scarring. In $72 \%$ of these scars in our series the aetiology was either documented or suspected infectious keratitis. ${ }^{3}$ Perforation of the cornea after keratitis occurs if treatment is not sought in the early stages. This neglect of initial keratitis leading to scars with iris incarceration partly reflects the inadequate eye care infrastructure, and partly the attitude towards seeking health care in the developing world.

Patients belonging to lower socioeconomic status in our series had a significantly higher risk of transplant failure after adjusting for the other risk factors. This may be related to poorer compliance with postoperative care of the transplants in this socioeconomic status, or to some undeciphered variables associated with lower socioeconomic status. Age $<10$ years at the time of transplant increased the risk of transplant failure significantly as compared with the $>10$ years age group. Reports from the developed world have also reported comparatively lower transplant survival rates in children. ${ }^{18} 19$

Vascularisation, superficial and deep considered together, of the host cornea before transplantation was associated in our series with significantly increased risk of transplant failure. The association of increased odds of transplant failure with deep vascularisation by itself was marginally significant in the univariate analysis, but this association was not significant in the multivariate analysis in our study. In reports from the developed world, presence of vascularisation without distinction between superficial and deep has been associated with significantly higher chance of transplant failure using univariate ${ }^{1415}$ and multivariate ${ }^{12}$ analysis, as has deep vascularisation by itself been associated significantly with transplant failure using univariate ${ }^{13}$ and multivariate ${ }^{17}$ analysis.

The age at which corneal transplants were done in our series, mean and median 41 years, is younger than that reported in the large series from the developed world..$^{132-24}$ Corneal blindness at younger productive age in the developing world has a worse socioeconomic impact, thereby drawing our attention more acutely towards this public health problem.

As a result of corneal transplantations in our series the percentage of blind eyes dropped from 80.2 to 41.8 . The odds of the eye being blind after transplantation were low for preoperative diagnoses of keratoconus and corneal dystrophies; moderate for pseudophakic bullous keratopathy and corneal scar other than adherent leucoma; and high for previous transplant failure, aphakic bullous keratopathy, mis- cellaneous causes including congenital conditions and glaucoma, and adherent leucoma. The odds of the eye being blind after transplantation were higher for lower socioeconomic status and age $<10$ years.

The data reported in this paper suggest that corneal transplantation can be a reasonably successful procedure in the developing world for some categories of preoperative diagnosis. For some other categories of preoperative diagnosis, and in the presence of certain risk factors, the survival rate of corneal transplants and visual outcome is poor, and caution may be exercised in attempting transplantation in such cases, especially because of the scarcity of donor corneas in the developing world. We estimate that currently only 15000 donor corneas are procured annually in India out of which a large proportion are unsuitable for transplantation. The requirement for donor corneas per year in India is at least 20 times the current procurement. This raises the need for quality eye banking in the developing world for procuring, handling, and storing donor corneas. The finding in the present study that even the use of fair quality donor cornea resulted in significantly higher risk of transplant failure than for the excellent, very good, or good grades of donor cornea underscores the need for maintaining high quality in eye banking for its success. Progress in eye banking is being made in some regions, but a lot more attention to eye banking is called for in order to meet the need in the developing world.

Increasing the number of ophthalmologists undergoing quality training in microsurgery is another requirement that needs to be met in order to deal with the present magnitude of corneal blindness in the developing world. In this area too, some institutions are attempting to meet this challenge; however, much more needs to be done. Efforts at improving the infrastructure and skilled staff, if combined with reliable data about what makes some cases of corneal blindness a good prognosis and others a bad prognosis for transplantation as suggested by this study, can enable more effective handling of blindness as a result of corneal diseases in the developing world.

The authors gratefully acknowledge Dr Soma Mandal, Dr Ravindranath Shenoy, and M Srinivas for help with data collection, and the staff of Information Systems Department at the L V Prasad Eye Institute for help with database programming.

1 Thylefors B, Negrel AD, Pararajasegaram R, Dadzie KY. Global data on blindness. Bull WHO 1995;73:115-21.

2 Yorston D, Wood M, Foster A. Penetrating keratoplasty in Africa: graft survival and visual outcome. Br f Ophthalmol 1996;80:890-4.

3 Dandona L, Ragu K, Janarthanan M, Shenoy R, Naduvilath TJ, Rao GN. Indications for penetrating keratoplasty in India. Indian f Ophthalmol 1997;45: (in press).

4 Kaplan EL, Meier P. Nonparametric estimation from incomplete observations. F Am Stat Assoc 1958;53:457-81. 5 Goodman LA, Kruskal WH. Measurements of association for cross classifications. F Am Stat Assoc 1954;49:732-64.

6 Goodman LA, Kruskal WH. Measurements of association for cross classifications. II. Further discussion and references. F Am Stat Assoc 1959;54:123-63.

7 Cox DR. Regression models and life tables. $\mathcal{F}$ R Stat Soc $\mathrm{Br}$ 1972;34:187-220.

8 Rosner B. Regression and correlation methods. In: Rosner B, ed. Fundamentals of biostatistics. Boston: PWS Publishers, 1986:369-441.

9 International statistical classification of diseases and related health problems. Tenth revision. Geneva: World Health health problems. Tenth revision.
Organisation, 1992;Vol 1:456. 
10 Rosner B. Statistical methods in ophthalmology: an adjustment for the intraclass correlation between eyes. Biometrics ment for the intracia

11 Ehlers N, Olsen T. Long-term results of corneal grafting in keratoconus. Acta Ophthalmol 1983;61:918-26.

12 Williams KA, Roder D, Esterman A, Muehlberg SM, Coster DJ. Factors predictive of corneal graft survival: report from the Australian Corneal Graft Registry. Ophthalmology 1992;99:403-14

13 Price FW, Whitson WE, Collins KS, Marks RG. Five-year corneal graft survival: large, single-center patient cohort. Arch Ophthalmol 1993;111:799-805.

14 Volker-Dieben HJ, Alphen CCK, Lansbergen Q, Persijn GG. Different influences on corneal graft survival in 539 transplants. Acta Ophthalmol 1982;60:190-202.

15 Bishop VLM, Robinson LP, Wechsler AW, Billson FA. Corneal graft survival: a retrospective Australian study. Aust
NZ f Ophthalmol 1986;14:133-8.

16 Kirkness CM, Ezra E, Rice NSC, Steele ADM. The success and survival of repeat corneal grafts. Eye 1990;4:58-64.

17 Vail A, Gore SM, Bradley BA, Easty DL, Rogers CA. Corneal graft survival and visual outcome: a multicenter study. Ophthalmology 1994;101:120-7.
18 Stulting RD, Sumers KD, Cavanagh HD, Waring GO, Gammon JA. Penetrating keratoplasty in children. Ophthalmology 1984;91:1222-30.

19 Cowden JW. Penetrating keratoplasty in infants and children. Ophthalmology 1990;97:324-9.

20 Gupta AK, Ellwein LB. The pattern of cataract surgery in India: 1992. Indian f Ophthalmol 1995;43:3-8.

21 Javitt JC. Cataract. In: Jamison DT, Mosley WH, Measham AR, Bobadilla JL, eds. Disease control priorities in developing countries. New York: Oxford University Press, 1993:63545.

22 Brady SE, Rapuano CJ, Arentsen JJ, Cohen EJ, Liabson PR. Clinical indications for the procedures associated with penetrating keratoplasty, 1983-1988. Am f Ophthalmol 1989; 108: 118-22.

23 Williams KA, Muehlberg SM, Wing SJ, Coster DJ. The Australian Corneal Graft Registry. 1990 to 1992 report. Aust NZ F Ophthalmol 1993;21 (suppl):1-48.

24 Vail A, Gore SM, Bradley BA, Easty DL, Rogers CA. Corneal transplantation in the United Kingdom and Republic of Ireland. Br f Ophthalmol 1993;77:650-6. 